\title{
Microbleeds in Alzheimer's Disease: A Neuropsychological Overview and Meta-Analysis
}

\author{
Amir A. Sepehry, Alexander Rauscher, Ging-Yuek Hsiung, Donna J. Lang
}

\begin{abstract}
The current literature on the role of brain microbleeds (MB) on the neuropsychological outcomes of Alzheimer's disease $(\mathrm{AD})$ is heterogeneous. We therefore meta-analytically examined the neuropsychological literature pertaining to MBs in AD. Using a priori selected criteria, studies with cross-sectional neuropsychological assessment on MBs and AD were reviewed. Six of 122 studies met selection criteria and provided neuropsychological data on either $\mathrm{AD}$ with MB and without MB, or in contrast to healthy controls. The global neuropsychological difference between $\mathrm{AD}$ with $\mathrm{MB}$ and $\mathrm{AD}$ without $\mathrm{MB}$ based on random effect model was nonsignificant, heterogeneous, and small (Effect Size $=-0.155 ; 95 \%$ confidence interval $=-0.465$ to 0.155 ; $\mathrm{p}$ value $=0.326$; Heterogenity: $\mathrm{Q}$-value $=12.744$; degrees of freedom $=5 ; \mathrm{p}=0.026 ; \mathrm{I}^{2}=61 \%$ ). The contribution of MBs to cognitive deficits in $\mathrm{AD}$ remains unclear. Future studies of $\mathrm{MB}$ in $\mathrm{AD}$ should strive to use standardized neuroimaging techniques with high sensitivity for $\mathrm{MB}$, a common standard for $\mathrm{MB}$ definition, and neuropsychological tests sensitive for detecting subtle cognitive impairment.
\end{abstract}

RÉSUMÉ: Microsaignements dans la maladie d'Alzheimer : aperçu neuropsychologique et méta-analyse. La littérature actuelle sur le rôle des microsaignements (MS) dans la maladie d'Alzheimer (MA) est hétérogène. Nous avons donc utilisé une méta-analyse pour examiner la littérature neuropsychologique sur les MS dans la MA. Nous avons revu les études sur les MS et la MA, choisies selon des critères de sélection déterminés a priori et rapportant une évaluation neuropsychologique transversale. Six études sur 122 rencontraient nos critères de sélection et présentaient des données neuropsychologiques soit sur des sujets atteints de MA avec MS et sans MS ou comparés à des volontaires sains. La différence neuropsychologique globale entre la MA avec et sans MS selon un modèle à effet aléatoire était non significative, hétérogène et faible (taille d'effet $\mathrm{d}=-0,155 ;$ intervalle de confiance à $95 \%=-0,465$ à $0.155 ; \mathrm{p}=0,326 ; \mathrm{q}=12,744 ;$ degrés de liberté $=5 ; \mathrm{p}=0,026 ; \mathrm{I}^{2}=61 \%$ ). La contribution des MS aux déficits cognitifs dans la MA demeure indéterminée. Des études sur les MS dans la MA devraient utiliser des techniques standardisées de neuroimagerie ayant une sensibilité élevée pour les MS, une définition standard commune des MS et des tests neuropsychologiques sensibles pour détecter un déficit cognitif subtil.

Keywords: Microbleed, Alzheimer's disease, Neuropsychology, Meta-analysis

doi:10.1017/cjn.2016.296

Can J Neurol Sci. 2016; 43: 753-759

\section{INTRODUCTION}

The loss of cognitive capacity is not a function of aging itself, but rather a marker of accumulated neuropathological changes over time. ${ }^{1}$ First described by Charcot and Bouchard ${ }^{2,3}$ as "miliary" aneurysms, cerebral microbleeds (MBs) are neurobiological markers of interest. The accumulation of MBs has been associated with decreased cognition in hypertensive patients, ${ }^{4}$ and the presence of lobar MBs has been associated with Alzheimer's disease (AD) ${ }^{5}$ resulting in prognostic significance. ${ }^{6-9}$ Additionally, MBs are indirectly affecting cognitive functioning as a result of antithrombotic therapy in the cases of atrial fibrillation and strokes ${ }^{10}$ or cerebral amyloid angiopathy. ${ }^{11,12}$ Likewise, MBs are considered to be an amyloid related imaging abnormality and are one of the exclusion criteria for entry into experimental amyloid-lowering therapies. ${ }^{13}$ Also, an increasing number of MBs is a strong predictor of mortality in $\mathrm{AD} .^{14}$
MBs in $\mathrm{AD}$ are thought to contribute to the pathophysiology of the illness ${ }^{6}$ and are identified in all cortical regions, infratentorially, and within the basal ganglia. Although their presence is associated with localized tissue damage, disruption of white matter structural integrity, ${ }^{15}$ and reduced cerebral blood flow, ${ }^{16}$ they have been thought as clinically silent in AD because the nature of their contributions to global cognition in $\mathrm{AD}$ is thought

From the Faculty of Medicine, Division of Neurology (AAS, G-YH), University

of British Columbia, Vancouver, Canada; Department of Paediatrics (AR), University of British Columbia, Vancouver, Canada; Department of Radiology (DL), University of British Columbia, Vancouver, Canada

Received January 6, 2016. Final Revisions Submitted July 3, 2016. Date of ACCEPTANCE July 8, 2016.

Correspondence to: Amir A. Sepehry, Division of Neurology, The University of British Columbia (UBC), UBC Hospital, Koerner Pavilion, S130 - 2211 Wesbrook Mall,

Vancouver, Canada V6T 2B5. E-mail: sepehryaa@alumni.ubc.ca.

Twitter: @asmetaanalysis. 
to be negligible, ${ }^{8}$ or at most unclear. ${ }^{7-9}$ The lack of a significant effect has been speculated to be due to small sample size, ${ }^{17}$ low MB counts, or severity of AD masking the subtle effect of MBs on cognition. ${ }^{9}$ Additionally, heterogeneous classifications and lack of validation of the definition of presence and prevalence of MBs have obscured the potential relationships between neurocognitive functioning and $\mathrm{MBs}$ in $\mathrm{AD}$. Furthermore, insensitivity of the assessment scales used to detect subtle cognitive deficits may have masked this effect. Many studies assessing global cognition in AD used the Mini Mental State Examination scale (MMSE), which is impervious to small subtle cognitive alterations. $^{18,19}$ However, literature in the Mild Cognitive Impairment (MCI) and aging literature suggest that MBs tend to impact cognitive functions, ${ }^{20}$ including processing speed, motor speed, ${ }^{21}$ attention-related impairment, ${ }^{22}$ memory, ${ }^{23}$ executive processing, ${ }^{1}$ and visuoconstructional function, ${ }^{24}$ and that MCI in the presence of $\mathrm{MBs}$ is potentially a predictor of progression to either AD or dementia. ${ }^{25,26}$

Because neuropsychological assessment plays a role in differential diagnosis and MBs potentially in cognitive impairment, ${ }^{27}$ better understanding of $\mathrm{MBs}$ on neuropsychological functioning in $\mathrm{AD}$ is a critical next step. The prevalence of MBs in $\mathrm{AD}$ in light of the neuroimaging, demographic, and clinical moderating factors was recently appraised. ${ }^{28}$ This meta-analysis showed that $\mathrm{MB}$ prevalence varies as a function of $\mathrm{AD}$ diagnosis, in that $\mathrm{MB}$ prevalence is higher for probable $\mathrm{AD}$ than for possible AD. Between studies, the strongest modifier of MB prevalence was neuroimaging modality, with susceptibility-weighted imaging $^{29}$ being twice as sensitive as conventional gradient echo magnetic resonance imaging (MRI).

Currently, little is known about the neuropsychological impact of $\mathrm{MB}$ in $\mathrm{AD}$. To date, most cross-sectional studies examining the impact of MBs on cognition in $\mathrm{AD}$ have has a small sample size. The difference between global cognitive scores in $\mathrm{AD}$ with and without $\mathrm{MB}$ is unclear. In this review and meta-analysis, we summarize findings and make sense of the dispersed knowledge about the neuropsychological impact of $\mathrm{MBs}$ in $\mathrm{AD}$. We sought to evaluate potential diagnostic and demographic moderating variables on the impact of $\mathrm{MBs}$ on global cognitive function. ${ }^{15,30}$

\section{MATERIALS AND METHODS}

\section{Search Strategies}

Search of Medline and EMBASE (on Ovid platform) was carried out on May 15, 2015, using a priori determined key terms. The following search strategy was used to identify study abstracts: [((Microbleed* or microhemorrhage or "petechial haemorrhage" or hemosiderin or "Cerebral amyloid angiopathy" or Cerebral Hemorrhage).mp. [mp = title, abstract, original title, name of substance word, subject heading word, keyword heading word, protocol supplementary concept word, rare disease supplementary concept word, unique identifier)) AND ((Alzheimer's disease or Dementia or Alzheimer*).mp. [mp =title, abstract, original title, name of substance word, subject heading word, keyword heading word, protocol supplementary concept word, rare disease supplementary concept word, unique identifier) AND (Cognitive or cognition or neuropsychology or neuropsychological).mp. $[\mathrm{mp}=$ title, abstract, original title, name of substance word, subject heading word, keyword heading word, protocol supplementary concept word, rare disease supplementary concept word, unique identifier]. Additionally, we examined the bibliographic sections of review papers relevant to the topic, and we referred to a meta-analysis conducted by our team on the prevalence of $\mathrm{MBs}$ in $\mathrm{AD}$ to substantiate our search of the literature. $^{28}$

\section{Data Analysis Methods}

Effect size [standardized mean difference, also known as Hedges' (adjusted) $g$, ES] was generated using mean, standard deviation, and sample size to examine the magnitude of group differences between $\mathrm{AD}$ with and without MBs, $\mathrm{AD}$ with MBs and healthy controls with MBs on neurocognitive functions. Betweenstudy heterogeneity was examined using the standard method of Q-value with $\mathrm{p}$ value and $\mathrm{I}^{2}$ to determine the existence and extent of variability. Based on current research theories, the extent of heterogeneity was examined. Publication bias was assessed by funnel plot and via quantitative analysis. The Begg and Mazumdar rank correlation test ${ }^{31}$ and Egger's test of the intercept tests ${ }^{32}$ were used to quantitatively appraise possible bias. A significant $p$ value for both Begg and Mazumdar and Egger's test is suggestive of bias. We have set to include cross-sectional studies examining cognition in $\mathrm{AD}$ with $\mathrm{MBs}$ versus $\mathrm{AD}$ without $\mathrm{MBs}$ or healthy control with MBs. We have excluded studies that included atypical $\mathrm{AD}$ such as frontal presentation or posterior cortical atrophy. Neuropsychiatric symptoms were examined if reported.

\section{ReSUlts}

\section{Study Selection Outcome}

The search of Medline and EMBASE on Ovid platform revealed 118 possible studies after duplicates were removed. Four additional studies that reported on cognitive functioning in $\mathrm{AD}$ with MBs emerged from reading of review papers and screening of the bibliographic section of the included studies. From a total of 122 studies, six met selection criteria and were included in the meta-analysis (supplementary Figure 1).

\section{Descriptive Statistics}

Six studies ${ }^{33-38}$ compared a total of 194 AD patients with MB $(\mathrm{AD}+\mathrm{MB})$ to $601 \mathrm{AD}$ patients without $(\mathrm{AD}-\mathrm{MB})$ on global cognitive functioning as assessed via MMSE. Among them, two studies $^{33,34}$ compared AD + MB to AD-MB on multiple cognitive functions. The neuropsychological tests included the Dementia rating scale, the Boston naming test, semantic fluency, phonemic fluency, the Wisconsin card sort test, the California verbal learning test, the Wechsler memory scale-revised for logical memory and delayed recall, the Boston judgment of line orientation, trail making test A and B, the western Aphasia battery with the apraxia subset, the Visual Association Task for object naming, and digit span forward and backward. These studies combined included $44 \mathrm{AD}+\mathrm{MB}$ and $99 \mathrm{AD}-\mathrm{MB}$.

One study $^{33}$ compared $\mathrm{AD}+\mathrm{MB}(\mathrm{n}=23)$ with healthy controls $(n=25)$ without cognitive impairment or vascular risk factors on a battery of neuropsychological tests assessing executive, global, language, memory, and attention functioning; and AD-MB $(\mathrm{n}=57)$. 
Globally, $59 \%$ to $100 \%$ of the MBs were reported to be lobar in location, and one study reported patients with mixed MB locations without reporting the percentage ${ }^{36}$ In terms of MB criteria, with the exception of one study, ${ }^{34}$ most included patients with $1 \mathrm{MB}$ or more. All but one study ${ }^{36}$ included patients with a diagnosis of probable AD. These studies reported susceptibility weighted imaging (SWI), Gradient echo (GE), and gradient echo Echo Planar Imaging (EPI) for detection of MB. The year of publication for the included studies ranged from 2006 to 2013 (Tables 1 and 2).

\section{Neuropsychological Findings: Global Cognition}

The aggregate standard difference in means between $\mathrm{AD}+\mathrm{MB}$ and $\mathrm{AD}-\mathrm{MB}$ for global cognitive functioning as measured by the MMSE was nonsignificant and heterogeneous (Q-value $=12.744$; degrees of freedom $\left.=5 ; \mathrm{p}=0.026 ; \mathrm{I}^{2}=60.766\right)$; Figure 1 . Heterogeneity, publication bias, and moderating variables are discussed in detail later.
For other cognitive domains, no aggregate can be generated given the low number of studies available for meta-analysis. However, these studies are descriptively examined (Figure 2).

\section{Neuropsychological Findings: Individual Cognitive Function}

Goos and colleagues reported that in 21 patients with and 42 without MBs, MBs were associated with cognitive dysfunction. ${ }^{34}$ They found that the MB group performed worse on test of language functioning including Visual Association Task-object naming and animal fluency. There was a difference in the neuropsychological tests results between unadjusted and adjusted analyses for age, sex, medial temporal lobe atrophy, and white matter hyperintensities. After adjustment, patients with multiple MBs performed worse on language functioning tasks and tests of working memory including digit span (forward and backward) than the group without MBs $(\mathrm{p}<0.05)$. Additionally, no significant associations between age and sex, with any of the

Table 1: Studies comparing AD with and without MB on neuropsychological functioning $(\mathrm{N}=6)$

\begin{tabular}{|c|c|c|c|c|c|c|c|c|c|}
\hline Studies & $\begin{array}{c}\text { MB } \\
\text { location }\end{array}$ & $\begin{array}{c}\text { MB } \\
\text { criteria }\end{array}$ & $\begin{array}{l}\text { AD type and } \\
\text { severity }\end{array}$ & $\begin{array}{l}\text { Scanning } \\
\text { technique }\end{array}$ & Scales & $\mathbf{A D}+\mathbf{M B}$ & $\mathbf{n}$ & AD-MB & $\mathbf{n}$ \\
\hline \multirow[t]{11}{*}{33} & \multirow[t]{11}{*}{$92 \%$ lobar } & \multirow[t]{11}{*}{$>1$} & \multirow[t]{11}{*}{ Probable AD } & \multirow[t]{11}{*}{ GRE/1.5 T/axial } & MMSE & $22.9(6.5)$ & 23 & $20.8(6.4)$ & 57 \\
\hline & & & & & Dementia rating scale & 115 ( 19.7) & 23 & $115(14.8)$ & 57 \\
\hline & & & & & Boston Naming test & $21.3(7.6)$ & 23 & $20.1(7.3)$ & 57 \\
\hline & & & & & Semantic fluency & $9.5(4.1)$ & 23 & $9.3(4.9)$ & 57 \\
\hline & & & & & Phonemic fluency & $9.7(5.7)$ & 23 & $8.9(4.2)$ & 57 \\
\hline & & & & & WCST-No correct & $40.5(9.2)$ & 23 & $40.6(9.7)$ & 57 \\
\hline & & & & & $\begin{array}{l}\text { California Verbal Learning } \\
\text { Test }\end{array}$ & $19.4(8.1)$ & 23 & $21.0(10.8)$ & 57 \\
\hline & & & & & $\begin{array}{l}\text { WMS-R-Logical memory } \\
\text { delayed recall }\end{array}$ & $6.8(4.9)$ & 23 & $2.0(2.6)$ & 57 \\
\hline & & & & & $\begin{array}{l}\text { Benton judgment of line } \\
\text { orientation }\end{array}$ & $15.9(11.1)$ & 23 & $18.0(8.0)$ & 57 \\
\hline & & & & & Trail B test & $340.9(402.2)$ & 23 & $227.1(199.3)$ & 57 \\
\hline & & & & & $\begin{array}{l}\text { Western Aphasia battery } \\
\text { apraxia subset }\end{array}$ & $57.3(2.5)$ & 23 & $54.0(10.3)$ & 57 \\
\hline \multirow[t]{8}{*}{34} & \multirow[t]{8}{*}{$94 \%$ Lobar } & \multirow[t]{8}{*}{$>8$} & \multirow[t]{8}{*}{ Probable AD } & \multirow{8}{*}{$\begin{array}{l}\text { GRE/1.5 T and } \\
\text { 1T/axial }\end{array}$} & MMSE & $17(7)$ & 21 & $22(4)$ & 42 \\
\hline & & & & & VAT & $4(4)$ & 21 & $6(4)$ & 42 \\
\hline & & & & & VAT-object naming & $10(3)$ & 21 & $12(1)$ & 42 \\
\hline & & & & & Animal fluency & $11(6)$ & 21 & $13(5)$ & 42 \\
\hline & & & & & Trail making test $\mathrm{A}$ & $127(78)$ & 21 & $97(88)$ & 42 \\
\hline & & & & & Trail making test $\mathrm{B}$ & $401(335)$ & 21 & $331(251)$ & 42 \\
\hline & & & & & Digit span forward & $10(2)$ & 21 & $11(2)$ & 42 \\
\hline & & & & & Digit span backward & $6(3)$ & 21 & $7(2)$ & 42 \\
\hline 35 & $69 \%$ Lobar & $>1$ & Probable AD & GRE/3T/axial & MMSE & $19.9(4.6)$ & 98 & $20.4(4.9)$ & 273 \\
\hline 36 & $\begin{array}{l}\text { Mixed locations, } 5 \text { not } \\
\text { provided }\end{array}$ & $>1$ & $\begin{array}{l}\text { Possible and } \\
\text { probable AD }\end{array}$ & GRE/1.5 T/ axial & MMSE & $21.3(3.8)$ & 7 & $19.3(5.4)$ & 35 \\
\hline 37 & $100 \%$ Lobar & $>1$ & Probable AD & SWI/1.5T & MMSE & $23(3)$ & 6 & $23(3)$ & 12 \\
\hline 38 & $59 \%$ Lobar & $>1$ & Probable AD & $\begin{array}{l}\text { GRE/1.5 \& } 1 \mathrm{~T} / \\
\text { axial }\end{array}$ & MMSE & $22(4)$ & 39 & $22(4)$ & 182 \\
\hline
\end{tabular}

$\mathrm{AD}=$ Alzheimer's disease CVLT $=$ California Verbal Learning Test; GE $=$ gradient echo; GRE $=$ gradient echo EPI; SWI $=$ susceptibility weighted imaging; MB: Microbleed; MMSE: Mini Mental State Examination; VAT = visual association task; WCST = Wisconsin Card Sort Test; WMS = Wechsler Memory Scale. No study reported neuropsychiatric evaluation. 
Table 2: Comparing mean cognitive scales scores between AD with MB and healthy control

\begin{tabular}{|c|c|c|c|c|c|c|c|}
\hline Studies & Scales & $\mathrm{AD}+\mathrm{MB}$ & $\mathbf{n}$ & Healthy control & $\mathbf{n}$ & Standard difference in mean & Degree of difference \\
\hline \multirow[t]{10}{*}{33} & California Verbal Learning Test & $19.4(8.1)$ & 23 & $48.8(9.8)$ & 25 & -3.2569 & Severe \\
\hline & Semantic fluency & $9.5(4.1)$ & 23 & 19.9 (4.4) & 25 & -2.4418 & Severe \\
\hline & MMSE & $22.9(6.5)$ & 23 & $28.7(1.2)$ & 25 & -1.2669 & Moderate \\
\hline & Boston Naming test & $21.3(7.6)$ & 23 & $28.6(1.1)$ & 25 & -1.3733 & Moderate \\
\hline & Phonemic fluency & $9.7(5.7)$ & 23 & $15.7(4.8)$ & 25 & -1.1429 & Moderate \\
\hline & WCST-No correct & $40.5(9.2)$ & 23 & $49.4(6.4)$ & 25 & -1.1317 & Moderate \\
\hline & WMS-R-Logical memory delayed recall & $6.8(4.9)$ & 23 & $13.3(2.9)$ & 25 & -1.6316 & Moderate \\
\hline & Benton judgment of line orientation & $15.9(11.1)$ & 23 & $25.6(3.4)$ & 25 & -1.2035 & Moderate \\
\hline & Trail B test & $340.9(402.2)$ & 23 & $69.6(20.8)$ & 25 & -0.9744 & Mild \\
\hline & Western Aphasia battery apraxia subset & $57.3(2.5)$ & 23 & $58.2(1.6)$ & 25 & -0.4328 & Mild \\
\hline
\end{tabular}

Note: CVLT = California Verbal Learning Test; MB = microbleeds; WCST = Wisconsin Card Sort Test; MMSE= Mini Mental State Examination;

WMS $=$ Wechsler Memory Scale. With the exception to aphasia rating, the different between-mean scores on the neurocognitive scales are nearly from 1 to 3.2 standard deviation unite. Cut of 1 standard difference in mean was used to separate degree of differences, where below 1 was considered mild, between 1 and 2 was considered moderate, and 2 and higher was considered severe cognitive difference.

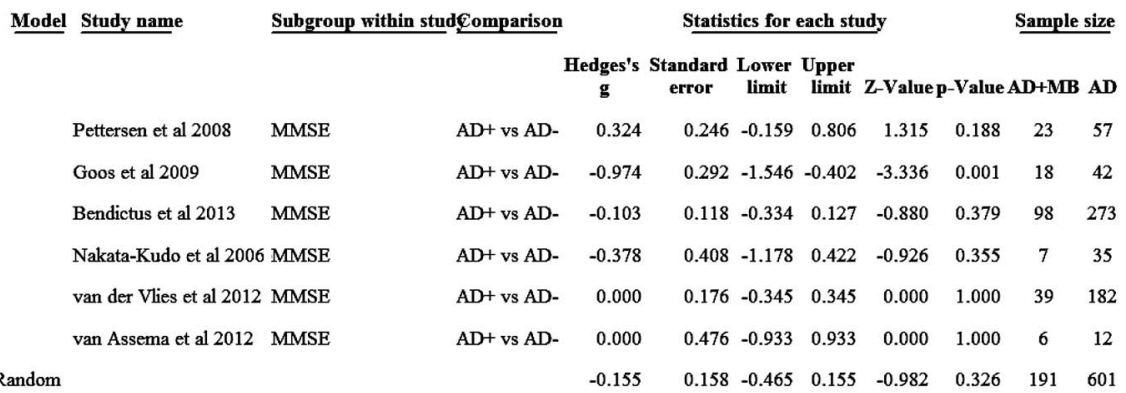

$\begin{array}{ll}\text { Study name } & \text { Subgroup within study } \\ & \\ \text { Pettersen et al 2008 } & \text { Benton judgment of line orientation } \\ \text { Pettersen et al 2008 } & \text { Boston Naming test } \\ \text { Pettersen et al 2008 } & \text { California verbal learning test } \\ \text { Pettersen et al 2008 } & \text { Dementia rating scale } \\ \text { Pettersen et al 2008 } & \text { Phonemic fluency } \\ \text { Pettersen et al 2008 } & \text { Semantic fluency } \\ \text { Pettersen et al 2008 } & \text { Trail making test B } \\ \text { Pettersen et al 2008 } & \text { WCST-Number correct } \\ \text { Pettersen et al 2008 } & \text { Western Aphasia battery apraxia subset } \\ \text { Pettersen et al 2008 } & \text { WMS-R-Logical memory delayed recall } \\ \text { Goos et al 2009 } & \text { Animal fluency } \\ \text { Goos et al 2009 } & \text { Digit span backward } \\ \text { Goos et al 2009 } & \text { Digit span forward } \\ \text { Goos et al 2009 } & \text { Trail making test A } \\ \text { Goos et al 2009 } & \text { Trail making test B } \\ \text { Goos et al 2009 } & \text { VAT-object naming } \\ \text { Goos et al 2009 } & \text { Visual association task (VAT) }\end{array}$

\begin{tabular}{l} 
Comparison \\
\hline$A D+$ vs $A D-$ \\
$A D+$ s $A D-$ \\
$A D+v s A D-$ \\
$A D+v s A D-$ \\
$A D+$ v $A D-$ \\
$A D+v s A D-$ \\
$A D+v s A D-$ \\
$A D+$ vs $A D-$ \\
$A D+$ s $A D-$ \\
$A D+v s A D-$ \\
$A D+$ vs $A D-$ \\
$A D+$ vs $A D-$ \\
$A D+v s A D-$ \\
$A D+v s A D-$ \\
$A D+v s A D-$ \\
$A D+$ vs $A D-$ \\
$A D+$ v $A D-$
\end{tabular}

$\begin{array}{ccccrrr}\begin{array}{c}\text { Hedges's } \\ \mathbf{g}\end{array} & \begin{array}{c}\text { Standard } \\ \text { error }\end{array} & \begin{array}{l}\text { Lower } \\ \text { limit }\end{array} & \begin{array}{c}\text { Upper } \\ \text { limit }\end{array} & \text { Z-Value } & \text { p-Value } \\ -0.232 & 0.245 & -0.712 & 0.249 & -0.944 & 0.345 \\ 0.161 & 0.245 & -0.319 & 0.641 & 0.657 & 0.511 \\ -0.157 & 0.245 & -0.637 & 0.323 & -0.640 & 0.522 \\ 0.000 & 0.245 & -0.479 & 0.479 & 0.000 & 1.000 \\ 0.170 & 0.245 & -0.311 & 0.650 & 0.692 & 0.489 \\ 0.042 & 0.245 & -0.437 & 0.522 & 0.173 & 0.863 \\ -0.414 & 0.247 & -0.898 & 0.070 & -1.677 & 0.094 \\ -0.010 & 0.245 & -0.490 & 0.469 & -0.042 & 0.966 \\ -0.370 & 0.246 & -0.853 & 0.113 & -1.503 & 0.133 \\ 1.394 & 0.268 & 0.868 & 1.920 & 5.196 & 0.000 \\ -0.372 & 0.286 & -0.932 & 0.188 & -1.303 & 0.192 \\ -0.416 & 0.267 & -0.938 & 0.107 & -1.560 & 0.119 \\ -0.494 & 0.268 & -1.018 & 0.031 & -1.845 & 0.065 \\ -0.346 & 0.298 & -0.931 & 0.239 & -1.159 & 0.247 \\ -0.256 & 0.335 & -0.912 & 0.400 & -0.765 & 0.444 \\ -1.079 & 0.295 & -1.658 & -0.501 & -3.659 & 0.000 \\ -0.494 & 0.277 & -1.036 & 0.048 & -1.785 & 0.074\end{array}$

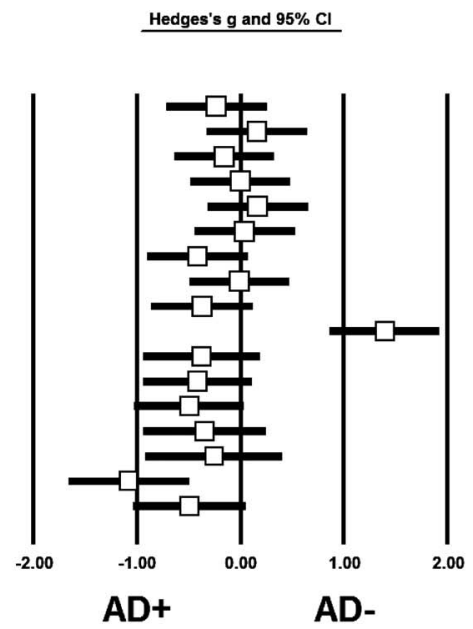

Figure 2: Presentation of the standard difference in means per scales and studies.

$\mathrm{AD}=$ Alzheimer's disease $\mathrm{AD}+=\mathrm{AD}$ with $\mathrm{MBs} ; \mathrm{AD}-=\mathrm{AD}$ without MBs; $\mathrm{CVLT}=\mathrm{California}$ Verbal Learning Test: $\mathrm{MB}=$ microbleed; MMSE = Mini Mental State Examination; N: number of studies, VAT=visual association task; WCST=Wisconsin Card Sort Test;

WMS $=$ Wechsler Memory Scale. 
neuropsychological measures, were reported. ${ }^{34}$ This suggests that not the demographic factors, but potentially other factors contribute to the presence or absence of cognitive impairment resulting from $\mathrm{MBs}$ in $\mathrm{AD}$ including medial temporal lobe atrophy and white matter hyperintensities. No significant group difference was observed on psychomotor speed (trail A) or executive functioning (trail B) in this study. The results of this study are striking given that this study included AD patients with eight or more MBs, which is suggestive of more severe angiopathy in line with vascular dementia or possible $\mathrm{AD}$, rather than probable $\mathrm{AD}$.

Pettersen and colleagues (33) reported on patients with $\mathrm{AD}+\mathrm{MB}(\mathrm{n}=23)$ in comparison to healthy controls $(\mathrm{n}=25)$ matched (age, sex, education). They reported on an AD sample with MBs consisting of lobar predominance in $92 \%$ of $\mathrm{AD}$ patients, with $57 \%$ of MBs being localized to occipital regions. Among controls, the occipital lobe was also the most common location for MBs. Nonetheless, because of sample size and test sensitivity, the authors suggested that they were unable to demonstrate an association between $\mathrm{MBs}$ and cognitive performance on individual domains. For cognitive comparison between $\mathrm{AD}+\mathrm{MB}$ and healthy adults as reported by Pettersen and colleagues, impairment was evident in the $\mathrm{AD}+\mathrm{MB}$ group on various functions and the deficits ranged from mild to severe, as examined by standard mean difference between two groups.

\section{Publication Bias, Heterogeneity, and Moderating Variables}

The results of the quantitative analyses were nonsignificant at alpha 0.05 , suggesting the absence of bias. There was betweenstudy heterogeneity in the results as observed by the $\mathrm{I}^{2}$ value $\left(\mathrm{I}^{2}>50 \%\right)$; one study seemed to act as an outlier given the use of more stringent criteria for MBs (e.g. > 8). After exclusion of this study from the global analysis, the global effect-size estimate was no longer heterogeneous $\left(\mathrm{I}^{2}=0.00\right)$.

Neither MRI scanning modality nor AD diagnosis significantly affected the effect-size estimate for global cognition. For scanning modality, no analysis was done for SWI $(\mathrm{N}=1)$, but for gradient echo EPI $(\mathrm{N}=5)$ a small effect-size estimate was obtained (Hedges' $g=-0.174$; 95\% confidence interval: -0.517 to 0.169 ; p value: $0.320 ; \mathrm{N}=5$; Q-value: 12.689 ; p-value: $0.013 ; \mathrm{I}^{2}$ : 68.476). For AD diagnosis, a lower effect-size estimate was obtained for the groups reporting on probable $\mathrm{AD}(\mathrm{N}=5)$ than for probable and possible $\mathrm{AD}(\mathrm{ES}=-0.132$ and -0.378 , respectively).

Mixed-effect univariate meta-regression was nonsignificant for percent lobar distribution, the year of publication, and imaging parameter (the field strength) on the global cognition as assessed by MMSE ( $\mathrm{p}=0.73,0.66$, and 0.862 , respectively).

Of note, other variables such as subject inclusion, including $\mathrm{AD}+\mathrm{MB}$ patients with variable number of bleeds (anywhere from one to many MBs), would have affected the differences in global cognitive functioning between groups. In the studies included here, individuals with variable numbers of bleeds were enrolled in the $\mathrm{AD}+\mathrm{MB}$ groups. Given the low number of studies available for analysis, further investigation of this factor was not performed because of the low probability of a reliable finding.

\section{DISCUSSION}

We have observed diversity across studies regarding differences between $\mathrm{AD}$ patients with and without MBs with respect to global cognition as assessed by MMSE. This variation in these differences appears to be the result of criteria of inclusion of MBs.

The identification of only one or more potential MBs is likely too low a threshold for inclusion given the concerns regarding accurate MB identification associated with imaging limitations. A better quantification approach will be to account both number and severity (size in diameter and location) of MBs instead of binary cutoff. Because the identification of MBs was based solely on visual ratings across these studies, image quality is a significant concern in the accurate identification of MBs. Although automated approaches exist at this time, this may not improve accurate identification of MBs because clinical judgement is required to differentiate true MBs from other susceptibility or flow effects in MRI. Accurate MB identification is strongly affected by imaging techniques. In our previously published work, ${ }^{28,39}$ SWI was determined to be the optimal imaging approach for MB identification. Here, only one of six of the currently reviewed studies employed SWI.

We found that none of the studies controlled for the effect of neuropsychiatric symptoms such as depression, which are likely to obfuscate the very subtle effects of MBs on cognitive impairment assessed by MMSE. ${ }^{40}$ Previously published data indicated that depressive symptoms are linked to cerebral small vessel disease such as $\mathrm{MBs},{ }^{41}$ even in the presence of silent brain infarct. ${ }^{42}$ This may suggest that the lack of difference between the homogeneous studies reporting on more than one $\mathrm{MB}$ is due to multiple reasons, and assessment of depression or other neuropsychiatric symptoms in $\mathrm{AD}$ when examining for $\mathrm{MBs}$ is recommended.

The major limitation of our study is the small number of included studies, especially those looking at MBs in multiple cognitive domains. We acknowledge that the research of neurocognitive functioning in relation to $\mathrm{MBs}$ in $\mathrm{AD}$ is relatively at an embryonic stage and it is typical to see few studies. How accurately the effects of MBs on individual cognitive domains can be interpreted remains challenging. Additionally, it is possible that MBs are just a by-product of amyloidosis present in AD and do not significantly affect cognitive functions. It is also possible that cognitive deficit in $\mathrm{AD}$ is overwhelmingly driven by $\mathrm{AD}$ pathology, and the emergence of MBs has comparatively minimal effects (compared with a vascular dementia case without underlying AD). These limitations warrant future studies. Furthermore, the number of subjects enrolled in these studies was limited, and that has potentially hindered further examination of the association between localized microbleeds (e.g. occipital lobes $)^{17}$ and cognitive performance in specific domain (e.g. visuospatial function). Although, as seen via meta-regression that we have found no positive effect regarding distribution of MBs across the included studies specific to AD patients, given the ecological evidence supporting the effect of localized MBs (lobar vs basal ganglia) and their count, ${ }^{43,44}$ the use of standardized neuroimaging technique for MB detection with larger sample size in future studies is warranted.

\section{CONCLUSION}

The role of $\mathrm{MB}$ on cognition in $\mathrm{AD}$ remains unclear because of limited number of neuropsychological studies. Future studies on MBs in AD should 1) use standardized imaging techniques with high sensitivity for MBs (i.e. SWI at 3T), 2) employ a common 
standard for MB definition, 3) use neuropsychological tests with high sensitivity, 4) compare pure $\mathrm{AD}$ patients to other dementia such as vascular dementia, and 5) screen for neuropsychiatric symptoms as possible confounders. Additionally, both severity (size and location) and number of MB should be recorded and reported. Taking these factors into consideration, further research in the field should be of interest and fruitful.

\section{SUPPLEMENTARY MATERIAL}

For supplementary material/s referred to in this article, please visit http://dx.doi.org/doi:10.1017/cjn.2016.296

\section{ACKNOWLEDGEMENTS}

AAS is funded by the Alzheimer Society of Canada and Canadian Consortium on Neurodegeneration in Aging. AR is supported by Canada Research Chairs.

\section{DISCLOSURES}

AAS has received a fellowship and postdoctoral grant from the Alzheimer Society of Canada and Canadian Consortium on Neurodegeneration in Aging. AR, G-YH, and DL do not have anything to disclose.

\section{STATEMENT OF AUTHORShIP}

AAS wrote the various drafts of the manuscript, designed the meta-analysis, and carried out the various meta-analytic procedures and statistics. AR, G-YH, and DL provided expertise on neuroimaging, and clinical expertise on the study's implication, and revised the manuscript for content.

\section{REFERENCES}

1. Meier IB, Gu Y, Guzaman VA, et al. Lobar microbleeds are associated with a decline in executive functioning in older adults. Cerebrovasc Dis. 2014;38:377-83.

2. Bouchard CJ. Etude sur quelques points de la pathogénie des hémorrhagies cérébrales; 1866.

3. Fagge $\mathrm{CH}$. The principles and practice of medicine. London, UK: J. \& A. Churchill; 1886

4. Huijts M, Duits A, van Oostenbrugge RJ, Kroon AA, de Leeuw PW, Staals J. Accumulation of MRI markers of cerebral small vessel disease is associated with decreased cognitive function. A study in first-ever lacunar stroke and hypertensive patients. Front Aging Neurosci. 2013;5:72

5. van Rooden S, Goos JD, van Opstal AM, et al. Increased number of microinfarcts in Alzheimer disease at 7-T MR imaging. Radiology. 2014;270:205-311.

6. Goos JD, van der Flier WM, Knol DL, et al. Clinical relevance of improved microbleed detection by susceptibility-weighted magnetic resonance imaging. Stroke. 2011;42:1894-900.

7. van der Flier WM. Clinical aspects of microbleeds in Alzheimer's disease. J Neurol Sci. 2012;322:56-8.

8. Cordonnier C, van der Flier WM. Brain microbleeds and Alzheimer's disease: innocent observation or key player? Brain. 2011;134:335-44.

9. Hommet C, Mondon K, Constans T, et al. Review of cerebral microangiopathy and Alzheimer's disease: relation between white matter hyperintensities and microbleeds. Dement Geriatr Cogn Disord. 2011;32:367-78.

10. Vernooij MW, Haag MD, van der Lugt A, et al. Use of antithrombotic drugs and the presence of cerebral microbleeds: the Rotterdam Scan Study. Arch Neurol. 2009;66:714-20.

11. Greenberg SM, Al-Shahi Salman R, Biessels GJ, et al. Outcome markers for clinical trials in cerebral amyloid angiopathy. Lancet Neurol. 2014;13:419-28.
12. Ringman JM, Sachs MC, Zhou Y, Monsell SE, Saver JL, Vinters HV. Clinical predictors of severe cerebral amyloid angiopathy and influence of APOE genotype in persons with pathologically verified Alzheimer disease. JAMA Neurol. 2014;71:878-83.

13. Sperling RA, Jack CR Jr., Black SE, et al. Amyloid-related imaging abnormalities in amyloid-modifying therapeutic trials: recommendations from the Alzheimer's Association Research Roundtable Workgroup. Alzheimers Dement. 2011;7:367-85.

14. Henneman WJP, Sluimer JD, Cordonnier C, et al. MRI biomarkers of vascular damage and atrophy predicting mortality in a memory clinic population. Stroke. 2009;40:492-8.

15. Akoudad S, Portegies ML, Koudstaal PJ, et al. Cerebral microbleeds are associated with an increased risk of stroke: the Rotterdam study. Circulation. 2015;132:509-16.

16. Gregg NM, Kim AE, Gurol $\mathrm{ME}$, et al. Incidental cerebral microbleeds and cerebral blood flow in elderly individuals. JAMA Neurol. 2015;72:1021-8.

17. Pettersen JA, Sathiyamoorthy G, Gao FQ, et al. Microbleed topography, leukoaraiosis, and cognition in probable Alzheimer disease from the Sunnybrook dementia study. Arch Neurol. 2008;65:790-5.

18. Clark CM, Sheppard L, Fillenbaum GG, et al. Variability in annual Mini-Mental State Examination score in patients with probable Alzheimer disease: a clinical perspective of data from the Consortium to Establish a Registry for Alzheimer's Disease. Arch Neurol. 1999;56:857-62.

19. Feher EP, Mahurin RK, Doody RS, Cooke N, Sims J, Pirozzolo FJ. Establishing the limits of the Mini-Mental State. Examination of 'subtests'. Arch Neurol. 1992;49:87-92.

20. Martinez-Ramirez S, Greenberg SM, Viswanathan A. Microbleeds do not affect rate of cognitive decline in Alzheimer disease. Neurology. 2013;80:1266.

21. Poels MMF, Ikram MA, van der Lugt A, et al. Cerebral microbleeds are associated with worse cognitive function: the Rotterdam Scan Study. Neurology. 2012;78:326-33.

22. van Norden AG, van den Berg HA, de Laat KF, Gons RA, van Dijk EJ, de Leeuw FE. Frontal and temporal microbleeds are related to cognitive function: the Radboud University Nijmegen Diffusion Tensor and Magnetic Resonance Cohort (RUN DMC) Study. Stroke. 2011;42:3382-6.

23. Staekenborg SS, Koedam ELGE, Henneman WJP, et al. Progression of mild cognitive impairment to dementia: contribution of cerebrovascular disease compared with medial temporal lobe atrophy. Stroke. 2009;40:1269-74.

24. Hilal S, Saini M, Tan CS, et al. Cerebral microbleeds and cognition: the epidemiology of dementia in Singapore study. Alzheimer Dis Assoc Disord. 2014;28:106-12.

25. Kirsch W, McAuley G, Holshouser B, et al. Serial susceptibility weighted MRI measures brain iron and microbleeds in dementia. J Alzheimers Dis. 2009;17:599-609.

26. Ayaz M, Boikov AS, Haacke EM, Kido DK, Kirsch WM. Imaging cerebral microbleeds using susceptibility weighted imaging: one step toward detecting vascular dementia. J Magnet ResonI Imaging. 2010;31:142-8.

27. Martinez-Ramirez S, Greenberg SM, Viswanathan A. Cerebral microbleeds: overview and implications in cognitive impairment. Alzheimer's Res Ther. 2014;6:33.

28. Sepehry AA, Lang D, Hsiung GY, Rauscher A. Prevalence of brain microbleeds in Alzheimer Disease: a systematic review and meta-analysis on the influence of neuroimaging techniques. AJNR Am J Neuroradiol. 2016;37:215-22.

29. Reichenbach JR, Venkatesan R, Schillinger DJ, Kido DK, Haacke EM. Small vessels in the human brain: MR venography with deoxyhemoglobin as an intrinsic contrast agent. Radiology. 1997;204:272-7.

30. Heringa SM, Reijmer YD, Leemans A, et al. Multiple microbleeds are related to cerebral network disruptions in patients with early Alzheimer's disease. J Alzheimers Dis. 2014;38:211-21.

31. Begg CB, Mazumdar M. Operating characteristics of a rank correlation test for publication bias. Biometrics. 1994;50:1088-101.

32. Egger M, Davey Smith G, Schneider M, Minder C. Bias in meta-analysis detected by a simple, graphical test. BMJ. 1997;315:629-34. 
33. Pettersen JA, Sathiyamoorthy G, Gao FQ, et al. Microbleed topography, leukoaraiosis, and cognition in probable Alzheimer disease from the Sunnybrook dementia study. Arch Neurol. 2008;65:790-5.

34. Goos JDC, Kester MI, Barkhof F, et al. Patients with Alzheimer disease with multiple microbleeds: relation with cerebrospinal fluid biomarkers and cognition. Stroke. 2009;40:3455-60.

35. Benedictus MR, Goos JDC, Binnewijzend MAA, et al. Specific risk factors for microbleeds and white matter hyperintensities in Alzheimer's disease. Neurobiol Aging. 2013;34:2488-94.

36. Nakata-Kudo Y, Mizuno T, Yamada K, et al. Microbleeds in Alzheimer disease are more related to cerebral amyloid angiopathy than cerebrovascular disease. Dement Geriatr Cogn Disord. 2006;22:8-14.

37. van Assema DM, Goos JD, van der Flier WM, et al. No evidence for additional blood-brain barrier P-glycoprotein dysfunction in Alzheimer's disease patients with microbleeds. J Cere Blood Flow Metab. 2012;32:1468-71.

38. van der Vlies AE, Goos JDC, Barkhof F, Scheltens P, van der Flier WM. Microbleeds do not affect rate of cognitive decline in Alzheimer disease. Neurology. 2012;79:763-9.
39. Denk C, Rauscher A. Susceptibility weighted imaging with multiple echoes. J Magn ResonI Imaging. 2010;31:185-91.

40. Feng C, Fang M, Xu Y, Hua T, Liu XY. Microbleeds in late-life depression: comparison of early- and late-onset depression. Biomed Res Int. 2014;2014:682092.

41. van Sloten TT, Sigurdsson S, van Buchem MA, et al. Cerebral small vessel disease and association with higher incidence of depressive symptoms in a general elderly population: the AGESReykjavik Study. Am J Psychiatry. 2015;172:570-8.

42. Wu RH, Feng C, Xu Y, Hua T, Liu XY, Fang M. Late-onset depression in the absence of stroke: associated with silent brain infarctions, microbleeds and lesion locations. Int J Med Sci. 2014;11:587-92.

43. Park J-H, Seo SW, Kim C, et al. Pathogenesis of cerebral microbleeds: in vivo imaging of amyloid and subcortical ischemic small vessel disease in 226 individuals with cognitive impairment. Ann Neurol. 2013;73:584-93.

44. Yakushiji Y, Noguchi T, Charidimou A, et al. Basal ganglia cerebral microbleeds and global cognitive function: the Kashima Scan Study. J Stroke Cerebrovasc Dis. 2015;24:431-9. 